\title{
INCENTIVO À CADEIA PRODUTIVA DO PALMITO PUPUNHA (Bactris gasipaes Kunth) ATRAVÉS DO APROVEITAMENTO INTEGRAL DA MATÉRIA-PRIMA
}

\section{INCENTIVE TO THE PRODUCTIVE CHAIN OF HEART OF PALM (Bactris gasipaes Kunth) PUPUNHA THROUGH THE COMPLETE UTILIZATION OF RAW MATERIALS}

\author{
Mariana Buranelo Egea ${ }^{1}$, Elida Simone Guido ${ }^{2}$, Beatriz Cervejeira Bolanho ${ }^{3}$, Jean Marcel Fuzi Pereira ${ }^{4}$, \\ Janaina Alves Magalhães ${ }^{5}$, Eliane Dalva Godoy Danesi ${ }^{6}$ \\ ${ }^{1}$ Universidade Federal do Paraná - UFPR - Curitiba - Brasil - mariegea@Imferreira.com \\ ${ }^{2}$ Universidade Federal do Rio Grande - FURG - Rio Grande - Brasil - elidaguido23@ hotmail.com \\ 3,4,5,6 Universidade Estadual de Maringá - UEM - Umuarama- Brasil - edgodoy@uem.br
}

\begin{abstract}
Resumo
A importância econômica e social do cultivo de palmito pupunha na região do Arenito/PR levou a elaboração de um esquema de processamento para o aproveitamento integral da matéria-prima, a fim de incentivar essa cadeia produtiva. Realizou-se o processamento de hastes de pupunha provenientes de lavouras com e sem irrigação, seguido pela análise do rendimento através de balanço de massa. Os resultados mostraram que a utilização de um sistema adequado de irrigação influencia de forma positiva no rendimento. O balanço de massa possibilitou comparar o rendimento em produtos na forma de conservas e minimamente processados e a quantidade de descartes e resíduos gerados. Os descartes foram transformados em farinhas para utilização como fonte de fibras. A parte destinada à produção de conservas foi dividida em 3 categorias: toletes (classe A), cubos (classe B) e cubos desuniformes (classe C), acondicionados em salmoura acidificada e submetidos ao tratamento térmico, resultando em produtos seguros para o consumo, com $\mathrm{pH}$ de equilíbrio abaixo de 4,5. O processamento mínimo realizado no trabalho acompanhou o tempo de vida de prateleira de toletes e cubos minimamente processados, tratados com acidificação (5\% de ácido cítrico) e armazenados a temperatura menor que $10^{\circ} \mathrm{C}$ em diferentes embalagens (PET e bandejas de isopor cobertas com filme PVC). Com as avaliações de pH $e$ acidez titulável realizadas foi possível verificar que os produtos atingiram $\mathrm{pH}$ na faixa segura, por volta de 4,5, sendo que nos cubos a acidificação foi mais eficiente que nos toletes. A tecnologia desenvolvida foi repassada aos interessados da região de abrangência de um projeto de extensão do Programa Universidade Sem Fronteiras.
\end{abstract}

Palavras-chave: palmito pupunha; rendimento; acidificação de conservas; produtos minimamente processados. 


\section{Introdução}

O desenvolvimento sustentável remete a iniciativas em que aspectos como o aproveitamento integral de matérias-primas agroecológicas minimizando a geração de resíduos ganham grande importância.

O cultivo da palmeira para obtenção de palmito constitui uma excelente alternativa para o cultivo sustentável na agricultura de pequeno porte. A industrialização aumenta o valor agregado, valoriza a agricultura e possibilita a exploração da cadeia produtiva na região. Como a maioria das espécies de palmeiras para obtenção de palmito é típica da Amazônia e Mata Atlântica, a implantação da cultura requer manejo adequado como irrigação. O custo desse sistema, no entanto, é convertido em maior rendimento da parte comestível e de produtos com textura adequada para o processamento.

Denomina-se palmito o produto comestível, de formato cilíndrico, macio e tenro, de sabor levemente adocicado, extraído da extremidade superior do estipe de certas palmeiras. É constituído, basicamente, pelo meristema apical e um número variável de folhas internas, ainda não plenamente desenvolvidas e imbricadas, sendo envolto e protegido pela bainha das folhas adultas, mais externas. O palmito é ainda rico em fibras, minerais, vitaminas, aminoácidos importantes e têm baixo valor calórico (GALDINO e CLEMENTE, 2008; MONTEIRO et al., 2002).

Diversas palmeiras proporcionam palmito comestível de valor comercial, mas pesquisas com a espécie Bactris gasipaes kunth, conhecido como palmito pupunha, têm se intesificado devido às vantagens econômicas: ser uma planta arbórea e perene, contribuindo para conservação do meio ambiente; ser cultivo de caráter conservacionista por minimizar os efeitos da erosão, podendo restabelecer a fertilidade do solo, através do manejo dos resíduos de colheita; apresentar maior rendimento por árvore; primeira colheita mais rápida; perfilhamento da planta mãe, permitindo cortes nos anos sebsequentes, apresenta escurecimento enzimático significativamente menor, sabor adocicado e textura macia. Quando comparado com outras espécies é importante alternativa agroecológica para diversificação da produção e fonte de renda (ANEFALOS et al., 2007; BELLEGARD et al., 2005; CHAIMSOHN et al., 2002; KULTCHETSCHI et al., 2001).

No processamento do palmito verifica-se que as hastes apresentam regiões de diferentes texturas e diâmetros, com a parte central tenra e uma extremidade fibrosa resistente. Estas características acarretam num rendimento relativamente baixo em conservas, com grande proporção de descartes e dificuldade de padronização dos produtos industrializados, devido à desuniformidade da matéria-prima. Além disso, o manejo cultural, como sistema irrigado ou não, também contribui nas variações de textura, rendimento e $\mathrm{pH}$. Por isso, estudos de desenvolvimento de tecnologias específicas para diferentes cultivos se justificam para viabilizar o sucesso da cadeia produtiva. 
A quantificação da parte fibrosa é uma etapa preliminar para estudos de caracterização e aproveitamento, com potencial destinação deste material para incorporação na alimentação humana e animal. As folhas, por exemplo, podem ser utilizadas para alimentação animal e adubação verde, já as cascas podem servir de alimento para animais e combustível para caldeiras. A parte fibrosa tem sido utilizada como ingrediente na fabricação de sopas desidratadas, conforme estudos realizados por Monteiro et al. (2002) e desenvolvimento de farinhas adequadas para incorporação em alimentos (BARBOSA et al., 2011).

Para o processamento de palmito pupunha em conservas é muito importante a garantia da segurança alimentar, evitando riscos ao consumidor. Isto porque a matéria-prima apresenta $\mathrm{pH}$ acima de 4,5 e as conservas, geram condições de anaerobiose que são favoráveis ao desenvolvimento da toxina botulínica. O Clostridium botulinum, bacilo Gram-positivo, se desenvolve em meio com baixa concentração de oxigênio, é produtor de esporos e é encontrado com frequência no solo, em legumes, verduras, frutas, fezes humanas e excrementos de animais. Sabe-se que o esporo só é inativado em processo de esterilização industrial em autoclaves e o meio ácido exerce inibição ao desenvolvimento do micro-organismo. Porém, o palmito apresenta alta sensibilidade térmica, o que impede que processo de esterilização seja realizado, pois o prejudica do ponto de vista sensorial, principalmente nos atributos que se referem à textura (BELLEGARD et al., 2005)

Dessa forma, é necessário um processamento envolvendo lavagem, desinfecção, acidificação adequada da salmoura, acondicionamento e tratamento térmico, além da adoção de sistemas como BPF (Boas Práticas de Fabricação) e APPCC (Análise de Perigos e Pontos Críticos de Controle). Assim, tem-se garantia da segurança do produto, condições higiênico-sanitárias adequadas dos estabelecimentos com a licença e o registro na Vigilância Sanitária para comercialização dos produtos.

O setor de hortaliças minimamente processadas constitui um segmento da agroindústria em crescimento, respondendo pela grande demanda por vegetais in natura, para utilização doméstica e empresarial proporcionando rapidez e praticidade no consumo, o que tem levado a um aumento na quantidade e variedade de produtos ofertados em feiras livres, pontos de conveniência e supermercados (FANTUZZI et al., 2004; KAPP et al., 2003).

O processamento mínimo de frutas e hortaliças é definido como a operação que elimina as partes não comestíveis, seguido pelo preparo adequado e prontos para consumo imediato, sempre mantido em refrigeração, sem que o vegetal perca a condição de produto fresco, com qualidade satisfatória sob os aspectos sensoriais e microbiológicos (SARZI e DURIGAN, 2002; PINELI et al., 2005). Por serem submetidos a severos estresses fisicos advindos do descascamento e corte, estes vegetais são mais perecíveis do que os intactos, pois há um aumento da taxa respiratória e da 
produção de etileno, com acelerada atividade enzimática devido à ruptura de células. A acidificação como etapa no processamento mínimo é uma alternativa já que os ácidos atuam como intensificadores do sabor e aroma, como tampões no controle do $\mathrm{pH}$, conservantes na prevenção do crescimento de micro-organismos, sinergistas aos antioxidantes na prevenção da rancidez e do escurecimento enzimático (CHITARRA e CHITARRA, 2006; DAMODARAN et al., 2010). Assim, assume determinante estratégia no palmito pupunha que apresenta $\mathrm{pH}$ na faixa de 6,0, para segurança do consumo aliado à utilização de embalagens permeáveis ao oxigênio, evitando anaerobiose.

Por estas razões, é importante o estudo de produtos que passam por processamento mínimo, para avaliar as características que definem sua qualidade e segurança, e o palmito pupunha minimamente processado é uma alternativa que possibilita a valorização da matéria-prima além da forma de conservas, que já são amplamente comercializadas.

A região do Arenito, no noroeste do estado do Paraná, vem se destacando na produção de palmito pupunha pelas características climáticas favoráveis. Dessa forma, buscou-se desenvolver uma tecnologia de processamento do palmito pupunha através da otimização do aproveitamento da matéria-prima, de forma a agregar valor e incentivar a cadeia produtiva. Ao final divulgaram-se os resultados aos interessados na região de abrangência de um projeto de extensão do Programa Universidade Sem Fronteiras.

\section{Material e Métodos}

O estudo foi realizado como atividade do projeto de extensão intitulado "Incentivo à cadeia produtiva do palmito pupunha através da otimização da produção e aproveitamento da matériaprima", do Programa Universidade Sem Fronteiras - Apoio à Agricultura Familiar da Secretaria de Estado Ciência, Tecnologia e Ensino Superior (SETI) do Estado do Paraná. Foram realizadas visitas técnicas aos produtores e processadores de palmito pupunha na região de abrangência do projeto para coletas de dados e de hastes de palmito pupunha cultivadas com e sem sistema de irrigação.

As hastes foram dirigidas ao Laboratório de Processamento de Vegetais da Universidade Estadual de Maringá, campus de UmuaramalPR e armazenadas em câmara fria até o processamento. Os reagentes foram de pureza garantida pelo fabricante. As bandejas de polietileno e filmes de PVC utilizadas foram sanitizadas juntamente com os utensílios antes do uso em solução de cloro a 200 ppm e as embalagens de vidro com tampas metálicas fervidas.

Foram coletadas 25 hastes das culturas irrigadas e não irrigadas em diferentes épocas do ano e foi feita uma média dos resultados do processamento em 5 diferentes lotes. Para realizar o balanço de massa as bainhas externas (cascas verdes), a parte fibrosa (caulinar) e as bainhas internas 
foram separadas e pesadas para obter o rendimento em produtos e subprodutos. A Figura 1 ilustra a metodologia adotada.

A parte comestível foi lavada e sanitizada em solução de cloro a 50 ppm por 10 minutos, enxaguada e dividida em 4 categorias de produtos. A etapa de branqueamento foi dispensada, visto que há relatos na literatura que comprovam o não escurecimento enzimático do palmito pupunha (GALDINO e CLEMENTE, 2008). A parte foliar foi processada na forma de minimamente processados (KAPP et al., 2003) e conservas acidificadas em toletes (classe A) e com a parte caulinar (basal) obteve-se conservas no formato de cubos (classe B) e cubos desuniformes (classe C).

Figura 1 - Esquema do processamento de palmito pupunha em diferentes produtos

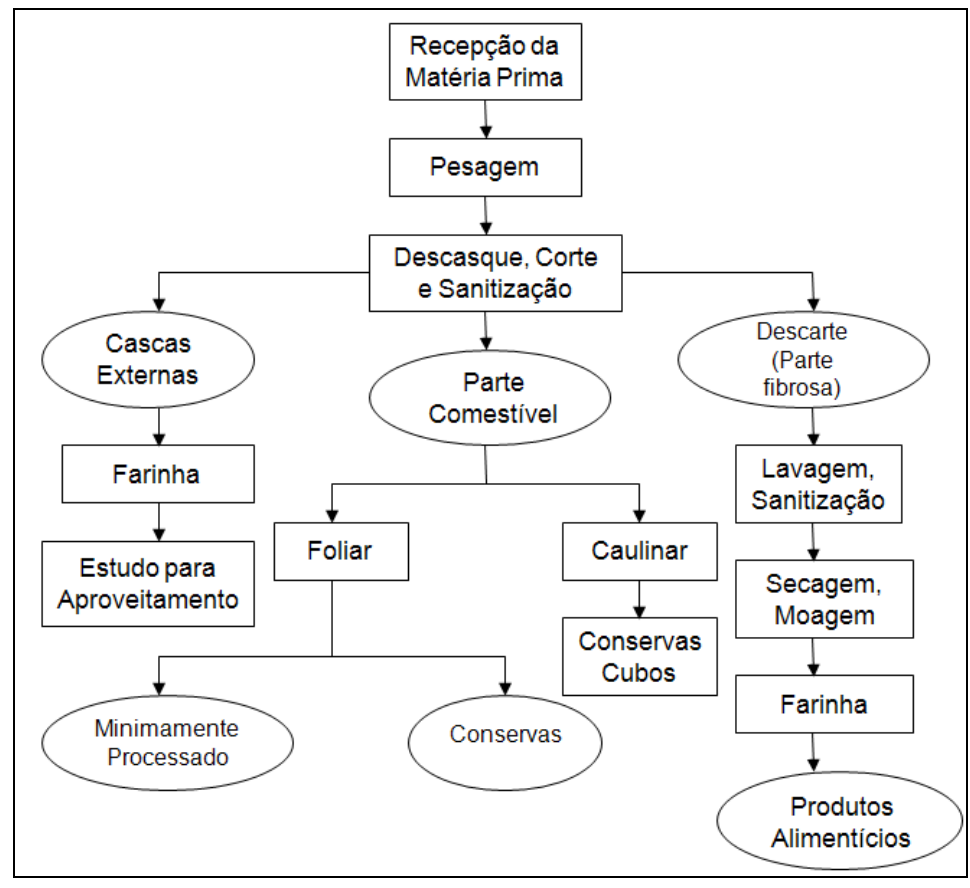

As conservas foram processadas de acordo com Paschoalino et al. (1997) e Bellegard et al. (2005). O palmito foliar (tolete) foi cortado com $9 \mathrm{~cm}$ de comprimento, o caulinar (basal) foi picado em cubos com cortador de legumes (VITALEX - Brasil) para obter uniformidade de tamanho e a parte final, de formato irregular, originou cubos desuniformes. Aproximadamente $300 \mathrm{~g}$ de palmito em cada formato foram colocados em frascos de vidro, previamente fervidos, seguidos da adição de salmoura acidificada com ácido cítrico. Para o cálculo da concentração ácida da salmoura, foram utilizados valores de referência de curvas de titulação previamente construídas através de procedimentos descritos por Pascoalino (1994).

Após o acondicionamento do palmito e da salmoura (com $4 \%$ de sal) a quente nos frascos de vidro, realizou-se a exaustão através da imersão dos frascos abertos em banho-maria por 30 minutos, seguido de fechamento. Os produtos foram pasteurizados por imersão em água em ebulição por 40 minutos no caso dos toletes e de 30 minutos para os cubos (tempo cronometrado a 
partir da ebulição) e os frascos foram resfriados até atingirem temperatura ambiente através de circulação de água.

Os produtos foram armazenados pelo período de quarentena (15 dias) à temperatura ambiente para avaliar os atributos de qualidade e o $\mathrm{pH}$ de equilíbrio atingido (entre 4,2 e 4,5). As análises realizadas foram acidez titulável, $\mathrm{pH}$ e medida da hermeticidade utilizando vacuômetro (SOLMASTER, Brasil) com faixa de leitura de 0 a 30 polHg. Foi realizado o teste de esterilidade comercial que visa observar a eficiência do tratamento térmico das conservas (DANESI e EGEA, 2010). As conservas foram processadas em cinco repetições, com distintos lotes de matérias-primas.

Para o processamento mínimo, os lotes foram separados em toletes e cubos, sendo realizada a sanitização por imersão em solução clorada a $50 \mathrm{ppm}$ por $10 \mathrm{~min}$. A acidificação foi feita com imersão em solução de ácido cítrico $5 \%$ por 15 minutos. O acondicionamento ocorreu em embalagens PET (polietileno) ou em bandejas de isopor cobertos com filme PVC, conforme a Tabela 1. Ensaios preliminares mostraram que o processamento mínimo em rodelas não foi bem sucedido porque houve destruição da estrutura original das rodelas, característica indesejável para o produto minimamente processado. Para obtenção de produtos com melhor padronização e aparência global as rodelas foram substituídas pelo formato de toletes e cubos. As amostras foram armazenadas em refrigeração a temperatura inferior a $10^{\circ} \mathrm{C}$. As análises de $\mathrm{pH}$ e acidez titulável para caracterização dos produtos foram realizadas no tempo inicial e em intervalos de 48 horas durante 6 dias como descrito no Instituto Adolfo Lutz (2005) e expressos como mL/100 g de produto fresco.

Tabela 1 - Tratamentos aplicados ao palmito pupunha minimamente processado em diferentes embalagens

\begin{tabular}{|c|c|c|c|}
\hline & Tratamento & Formato & Embalagem \\
\hline 1 & Controle* & Cubos & $\begin{array}{c}\text { Bandejas de isopor envoltas por } \\
\text { filme PVC }\end{array}$ \\
\hline 2 & Controle* & Toletes & $\begin{array}{c}\text { Bandejas de isopor envoltas por } \\
\text { filme PVC }\end{array}$ \\
\hline 3 & Imersão em solução de ácido cítrico 5\% & Cubos & $\begin{array}{c}\text { Bandejas de isopor envoltas por } \\
\text { filme PVC }\end{array}$ \\
\hline 4 & Imersão em solução de ácido cítrico 5\% & Toletes & $\begin{array}{c}\text { Bandejas de isopor envoltas por } \\
\text { filme PVC }\end{array}$ \\
\hline 5 & Controle* & Cubos & PET com tampa \\
\hline 6 & Controle* & Toletes & PET com tampa \\
\hline 7 & Imersão em solução de ácido cítrico 5\% & Cubos & PET com tampa \\
\hline 8 & Imersão em solução de ácido cítrico 5\% & Toletes & PET com tampa \\
\hline
\end{tabular}

* - imersão apenas em água potável

O descarte fibroso, localizado na extremidade caulinar, apresentou textura inadequada para processamento, verificado pela resistência ao corte. Dessa forma, foi destinado para o processamento de farinha através de secagem em estufa com circulação forçada, seguido de trituração em moinho de facas (SL031, SOLAB, Brasil). A granulometria da farinha foi definida 
para classificação como pó fino, determinada em conjunto de peneiras com malhas de 25 a 80 USS \ASTM, submetidas à ação de vibrador pelo período de 10 min (PROTZEK et al., 1998) expressa em porcentagem de material retido em cada peneira.

A determinação da composição centesimal das farinhas produzidas nas diferentes granulometrias foi realizada adotando os métodos oficiais segundo AOAC (2007). O valor calórico do produto foi calculado com base na composição centesimal utilizando-se os fatores de conversão de Atwater de $4 \mathrm{kcal} / \mathrm{g}$ para proteínas, $9 \mathrm{kcal} / \mathrm{g}$ para lipídios e $4 \mathrm{kcal} / \mathrm{g}$ para carboidratos (PEREIRA et al., 2005).

\section{Resultados e Discussão}

O balanço de massa do processamento de pupunhas provenientes de lavouras com e sem irrigação está exposto na Figura 2. Pode-se notar que a irrigação proporcionou a obtenção de maior porcentagem de parte comestível, destinada à elaboração de diferentes produtos. Além disso, a utilização de sistema de irrigação possibilita o corte do palmito a partir de 18 meses de plantio, enquanto as lavouras não irrigadas apresentam desenvolvimento inicial mais lento, sendo o primeiro corte realizado entre 24 e 36 meses. Outra desvantagem das lavouras não irrigadas é a diminuição do rendimento nos períodos de estiagem, devido à menor quantidade de água disponível no solo. A colheita do palmito pupunha pode ser feita quando o caule apresentar $9 \mathrm{~cm}$ de diâmetro. Mas o formato demandado pelo mercado e o período de chuvas para evitar deficit hídrico podem influenciar nesse parâmetro (BELLEGARD et al., 2005).

$\mathrm{Na}$ produção de conservas utilizaram-se as diferentes porções do palmito de acordo com a sua textura. O tolete (conserva classe A), região mais nobre e macia, apresentou menor rendimento que a região caulinar ou basal, destinada a conserva em cubos (classe B). A porção inferior da haste com textura inadequada para conservas classes A e B, foi destinada para produção das conservas classe $\mathrm{C}$, a qual apresentou menor rendimento e valor agregado entre as classes.

O palmito irrigado apresentou em média $450 \mathrm{~g}$ de tolete por haste, $16 \%$ a mais que o não irrigado (210 g/haste), havendo uma diferença de $11 \%$ em relação à parte caulinar (conserva classe B). Os resultados obtidos estão de acordo com os dados do Instituto Agronômico do Paraná (IAPAR, 2001), em que o tolete pesa de 200 a 250 g, podendo chegar a 480 g e o palmito caulinar (basal) pesa de 120 a $300 \mathrm{~g}$, podendo atingir $800 \mathrm{~g}$. Morsbach et al. (1998) realizaram cortes de palmito pupunha na época de chuvas em Morretes, litoral do Estado do Paraná, que renderam em média $480 \mathrm{~g}$ de palmito tolete e $720 \mathrm{~g}$ de palmito caulinar (basal) e apical. O palmito apical, localizado no ápice do talo (classe C), apresentou rendimento de $70 \mathrm{~g} / \mathrm{haste}$ de palmito irrigado e 80 g/haste de palmito não irrigado, valores condizentes com os relatados pelo IAPAR (2001) de 30 a $120 \mathrm{~g}$. 
Em relação aos subprodutos do processamento do palmito pupunha, a cultura não irrigada proporcionou maior quantidade de bainhas externas e internas (15,5\% a mais que a cultura irrigada), que correspondem à casca e possuem menor valor agregado, sendo geralmente destinada a alimentação animal. A porção fibrosa, com textura inadequada para elaboração de produtos como conservas e minimante processados, foi destinada a elaboração de farinha. Este aproveitamento diminui a quantidade de resíduos gerados no processamento do palmito pupunha, que corresponde a $33,3 \%$ na cultura irrigada e $22,7 \%$ na não irrigada, e agrega valor a cadeia produtiva. Esta alternativa reveste-se de importância quando somada aos descartes das bainhas, o que geraria em média $84 \%$ de resíduos.

Figura 2 - Balanço de massa do processamento de palmito pupunha com e sem irrigação

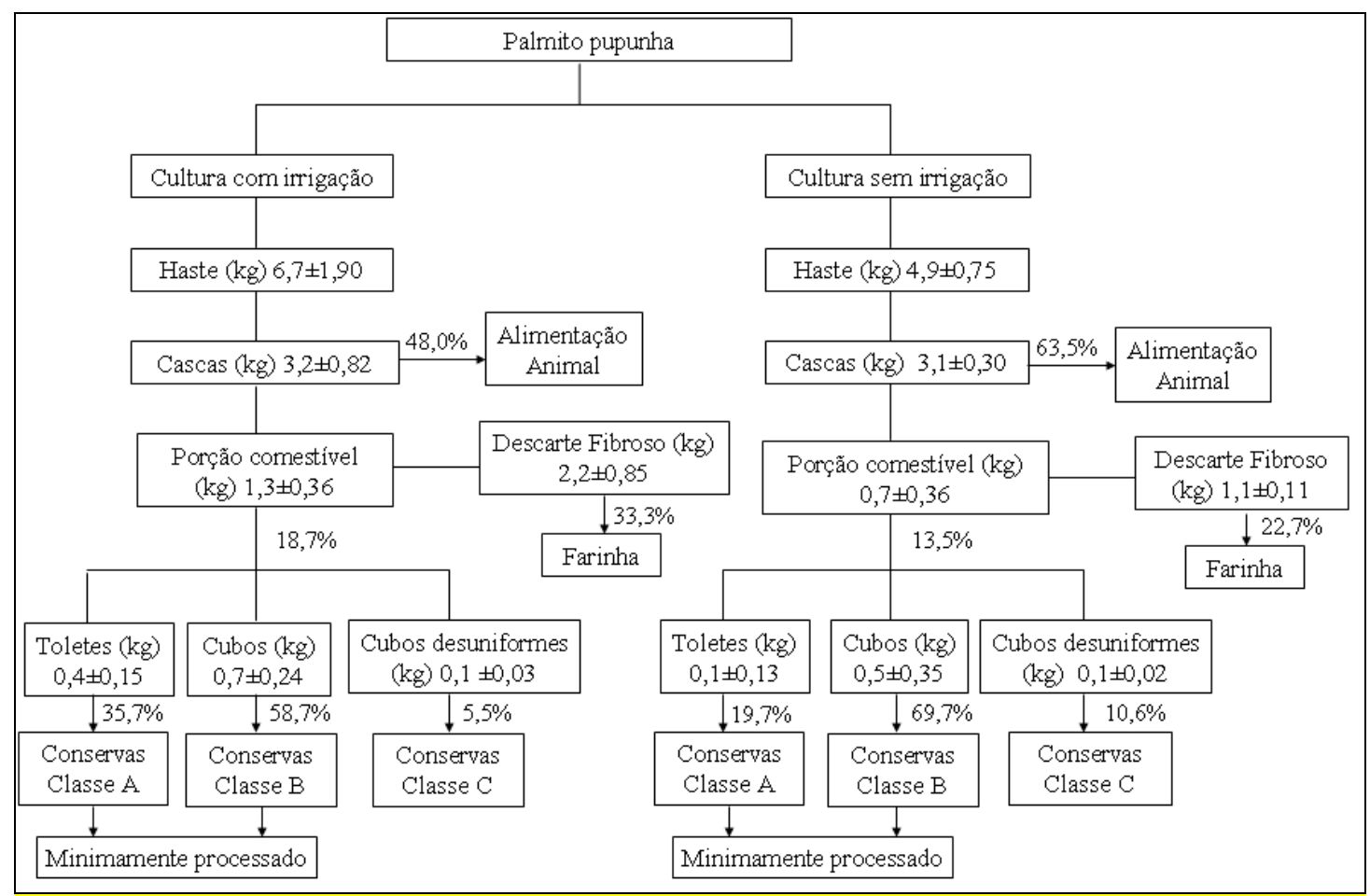

Considerando o valor nutricional da porção fibrosa descartada e visando proporcionar maior retorno econômico para o pequeno produtor, foi realizada a secagem para elaboração da farinha. Houve eliminação de aproximadamente $88 \%$ de água, resultando em rendimento total em torno de 267,6g e 133,5g de farinha por haste, para a cultura irrigada e não irrigada, respectivamente. Esta farinha após passar por conjunto de peneiras atingiu granulometria adequada para elaboração de diversos produtos, com destaque para os de panificação. A composição centesimal da farinha produzida e separada em diferentes granulometrias pode ser observada na Tabela 2.

As farinhas obtidas se destacaram pelo elevado teor de fibras, com destaque para a farinha retida na terceira peneira (32 mesh). O teor de umidade e proteínas das farinhas foi similar à farinha 
de trigo (13\% de umidade e 9,8\% de proteína) (TACO, 2011). Embora sejam proteínas de funcionalidade diferentes, a farinha de pupunha ganha interesse pelos baixos teores de lipídios e consideráveis teores de fibras e cinzas, tornando-a promissora para a incorporação em alimentos.

Tabela 2 - Composição centesimal da farinha em diferentes granulometrias produzidas com descarte do processamento de conservas de palmito pupunha

\begin{tabular}{|c|c|c|c|c|c|}
\hline Componente & $\begin{array}{c}20 \text { mesh } \\
(0,85 \mathrm{~mm})\end{array}$ & $\begin{array}{c}28 \mathrm{mesh} \\
(0,60 \mathrm{~mm})\end{array}$ & $\begin{array}{c}32 \mathrm{mesh} \\
(0,50 \mathrm{~mm})\end{array}$ & $\begin{array}{c}48 \text { mesh } \\
(0,30 \mathrm{~mm})\end{array}$ & $\begin{array}{l}100 \mathrm{mesh} \\
(0,15 \mathrm{~mm})\end{array}$ \\
\hline Umidade & $13,78 \pm 0,03^{\mathrm{a}}$ & $12,20 \pm 0,02^{b}$ & $11,43 \pm 0,05^{b}$ & $11,30 \pm 0,03^{b}$ & $11,91 \pm 0,01^{\mathrm{b}}$ \\
\hline Cinzas & $6,02 \pm 0,02^{\mathrm{a}}$ & $5,02 \pm 0,04^{\mathrm{b}}$ & $4,65 \pm 0,09^{b}$ & $4,78 \pm 0,08^{\mathrm{b}}$ & $5,13 \pm 0,01^{b}$ \\
\hline Proteínas & $8,02 \pm 0,07^{\mathrm{a}}$ & $6,63 \pm 0,02^{\mathrm{b}}$ & $6,07 \pm 0,05^{\mathrm{b}}$ & $6,58 \pm 0,03^{b}$ & $7,19 \pm 0,05^{\mathrm{b}}$ \\
\hline Lipídios & $1,27 \pm 0,03^{\mathrm{a}}$ & $1,14 \pm 0,05^{\mathrm{a}}$ & $1,14 \pm 0,03^{\mathrm{a}}$ & $1,20 \pm 0,01^{\mathrm{a}}$ & $1,53 \pm 0,03^{\mathrm{a}}$ \\
\hline Fibra Bruta & $26,16 \pm 0,09^{c}$ & $32,51 \pm 0,04^{\mathrm{b}}$ & $34,17 \pm 0,18^{\mathrm{a}}$ & $31,70 \pm 0,01^{\mathrm{b}}$ & $29,69 \pm 0,29^{b}$ \\
\hline Carboidratos* & 44,75 & 42,50 & 42,54 & 44,44 & 44,28 \\
\hline Valor Calórico $(\mathrm{kcal})^{* *}$ & 222,51 & 206,78 & 204,7 & 214,88 & 219,65 \\
\hline
\end{tabular}

* Os carboidratos foram calculados por diferença

** O valor calórico foi calculado segundo Pereira et al. 2005

O processamento de conservas nas 3 categorias citadas possibilitou a obtenção de produtos seguros para o consumo, de excelente aparência, apresentando salmoura transparente e límpida, toletes e cubos íntegros, com textura e sabor típicos. É importante verificar as embalagens quanto aos aspectos de qualidade, que consistem dentre outros, na turvação da salmoura, estufamento da tampa metálica, vazamentos e deterioração.

No mercado observa-se a disponibilidade das 3 categorias de conservas, o que possibilita a oferta de produtos para diferentes consumidores, uma vez que o preço é bastante variável e nesse sistema, toda a cadeia produtiva é beneficiada. As conservas A são indicadas para saladas e aperitivos, as B e C são adequadas para recheios de tortas, pastéis e pizzas.

Os resultados referentes às análises realizadas nas conservas processadas após a quarentena estão expressos na Tabela 3 e atendem aos requisitos da legislação vigente. Os testes de esterilidade apresentaram resultados negativos, confirmando que não ocorreu crescimento microbiano. $\mathrm{O}$ vácuo, que comprova a hermeticidade da embalagem com perfeita vedação da tampa, apresentou resultados satisfatórios entre 15 a 18 pollHg. Esses valores encontram-se dentro da faixa preconizada pela legislação (BRASIL, 1999), estipulada como superior a 10 pollHg. O pH das conservas manteve-se adequado, em torno de 4,5, o que garante a segurança sob o aspecto microbiológico. Em todos os lotes processados os índices exigidos pela legislação foram assegurados, e não ocorreram diferenças significativas entre os mesmos, enfatizando a eficiência da metodologia adotada. 
Tabela 3 - Avaliação da qualidade das conservas de palmito pupunha processadas em diferentes categorias acondicionadas em frascos de vidro de $300 \mathrm{~g}$

\begin{tabular}{ccccccc}
\hline Conservas & Análises & \multicolumn{5}{c}{ Processamentos - lotes } \\
\cline { 3 - 6 } & & $\mathbf{1}$ & $\mathbf{2}$ & $\mathbf{3}$ & $\mathbf{4}$ & $\mathbf{5}$ \\
\hline \multirow{2}{*}{ Classe A } & Esterilidade* & - & - & - & - & - \\
& Vácuo $(\mathrm{pol} / \mathrm{Hg}) * *$ & $18^{\mathrm{a}}$ & $16^{\mathrm{ab}}$ & $16^{\mathrm{ab}}$ & $16^{\mathrm{ab}}$ & $15^{\mathrm{b}}$ \\
& $\mathrm{pH}$ & $4,47^{\mathrm{a}}$ & $4,38^{\mathrm{ab}}$ & 4,33 & $4,41^{\mathrm{ab}}$ & $4,45^{\mathrm{ab}}$ \\
& Esterilidade & - & - & - & - & - \\
Classe B & Vácuo (pol/Hg) & $15^{\mathrm{a}}$ & $17^{\mathrm{ab}}$ & $18^{\mathrm{b}}$ & $17^{\mathrm{ab}}$ & $16^{\mathrm{ab}}$ \\
& $\mathrm{pH}$ & $4,40^{\mathrm{ab}}$ & $4,42^{\mathrm{ab}}$ & $4,29^{\mathrm{ac}}$ & $4,45^{\mathrm{ac}}$ & $4,56^{\mathrm{c}}$ \\
& Esterilidade & - & - & - & - & - \\
Classe C & Vácuo (pol/Hg) & $16^{\mathrm{ab}}$ & $18^{\mathrm{b}}$ & $15^{\mathrm{a}}$ & $15^{\mathrm{a}}$ & $14^{\mathrm{a}}$ \\
& $\mathrm{pH}$ & $4,46^{\mathrm{ab}}$ & $4,39^{\mathrm{ab}}$ & $4,29^{\mathrm{b}}$ & $4,48^{\mathrm{a}}$ & $4,44^{\mathrm{a}}$ \\
\hline
\end{tabular}

* resultados negativos (-) não apresentaram turvação para mesófilos a $35^{\circ} \mathrm{C}$ por 5 dias e termófilos a $55^{\circ} \mathrm{C}$ por 5 dias

**pesquisa de hermeticidade

Letras minúsculas iguais nas colunas não diferem ao nível de 5\% de significância pelo teste de Tukey

Como a matéria-prima apresenta pH na faixa de 5,8 a 6,2, variação decorrente das condições culturais (BERBARI et al., 2008), a acidificação realizada para atingir o pH de equilíbrio inferior a 4,5, após quarentena foi eficiente. Cabe ressaltar que a cada lote processado, uma curva de titulação deve ser construída para garantir que as variações inerentes à matéria-prima não comprometam esse parâmetro tão importante. As determinações de pH como controle de qualidade após a quarentena são essenciais, pois garantem que interações da salmoura e palmito, bem como variações na proporção da salmoura e cubos ou toletes, não interferirão no valor do $\mathrm{pH}$ de equilíbirio, o que comprometeria a conservação eficiente do produto no período estipulado como vida de prateleira.

A aplicação do tratamento térmico em binômios de tempo e temperatura definidos como pasteurização em banho-maria, possibilitou a manutenção da integridade dos cubos e toletes, não danificando a textura, o que afetaria a aparência dos produtos. A combinação com a acidificação adequada estabeleceu condições impróprias para o desenvolvimento do Clostridium botulinum, garantindo a segurança de consumo das conservas nas categorias processadas. A esterilidade comercial das conservas foi atingida com ausência de crescimento de micro-organismos mesófilos e termófilos acidotolerantes, bolores e leveduras (BERBARI et al., 2008).

A Tabela 4 apresenta os resultados obtidos nos experimentos com o processamento mínimo de palmito pupunha.

Foi possível comprovar que o tratamento com acidificação comparado com o tratamento controle, considerando os formatos e as embalagens utilizadas, diminuiu o $\mathrm{pH}$ significativamente ( $\mathrm{p}<0,05)$. No caso da acidez titulável não ocorreu diferença significativa entre o controle e a imersão em ácido no tratamento de toletes embalados em bandejas de isopor com filme PVC no tempo inicial. 
Tabela 4 - Valores de pH e acidez titulável de palmito pupunha minimamente processado em toletes e em cubos, armazenados em embalagens PET e bandejas de isopor

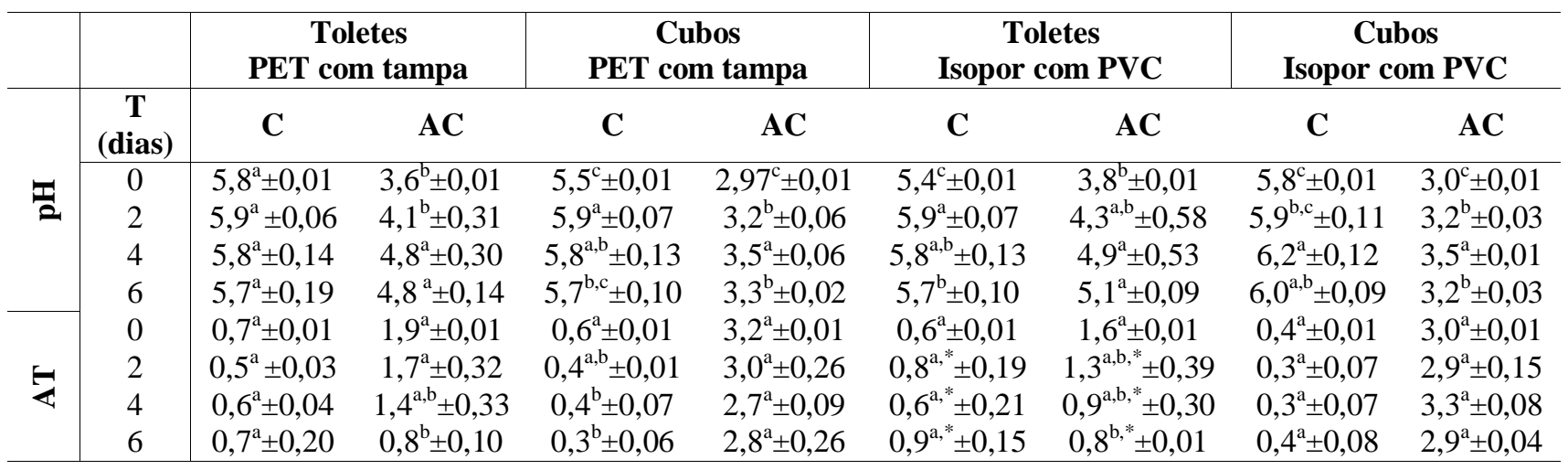

AT - acidez titulável, T - tempo, C - tratamento controle (sem acidificação), AC - tratamento com imersão em solução de $5 \%$ de ácido cítrico.

${ }^{\mathrm{a}, \mathrm{b}, \mathrm{c}}$ médias de diferentes tratamentos (variando o tempo de vida de prateleira) com letras minúsculas iguais não diferem ao nível de $5 \%$ de significância pelo teste de Tukey.

*médias de diferentes tratamentos (variando entre controle e acidificação na mesma embalagem e mesmo formato) com asterisco não diferem ao nível de 5\% de significância pelo teste de Tukey.

$\mathrm{O}$ armazenamento não modificou de forma significativa o $\mathrm{pH}$ dos toletes de palmito minimamente processados em embalagens PET com tampa. No entanto, para os acidificados houve aumento significativo após o $4^{\circ}$ dia de armazenamento que se manteve até o $6^{\circ}$ dia, o que também ocorreu com os toletes acidificados minimamente processados em embalagens de isopor com filme PVC. Este aumento de pH no período de armazenamento também foi verificado por Junqueira et al. (2009) que utilizou ácido ascórbico juntamente com ácido cítrico no tratamento de batatas. No entanto, Teixeira et al. (2001) não encontraram diferença significativa entre os tempos de armazenamento.

É aconselhável que o processamento mínimo de palmito pupunha seja realizado de forma a garantir pH na faixa de 4,5 através da acidificação. Mesmo não sendo previsto por legislação para estes produtos, esta é uma maneira de garantir segurança microbiológica devido à possibilidade de contaminação com Clostridium botulinum em produtos manipulados inadequadamente. Nestes casos, é necessário considerar que embalagens permeáveis a oxigênio devem ser utilizadas evitando anaerobiose favorável ao desenvolvimento deste micro-organismo (CHITARRA e CHITARRA, 2006). Nos ensaios realizados com imersão em ácido cítrico após o período de 4 dias em refrigeração, os toletes acondicionados em bandejas de isopor apresentaram valores de $\mathrm{pH}$ superiores a 4,5 e os produtos na forma de cubos permaneceram até o $6^{\circ}$ dia com pH abaixo de 4,5, apresentando-se seguros para o consumo. Dos tratamentos avaliados o formato de cubos por apresentar maior superfície de contato, absorvendo o ácido de forma mais eficiente, mantiveram o pH no limite seguro durante o período de armazenamento indicado neste trabalho. 
Os toletes de palmito minimamente processado sem o tratamento de acidificação (controle) embalados em PET e bandejas de isopor com filme PVC não apresentaram diferença entre a acidez titulável nos tempos de armazenamento. O mesmo aconteceu com os cubos acidificados embalados em PET e em bandejas de isopor com filme PVC. Para os toletes houve diferença na acidez durante o armazenamento com uma tendência decrescente (diminuição da acidez com o aumento do tempo de armazenamento), devido à menor difusão do ácido. Diferente do que foi encontrado neste trabalho, Arruda et al. (2003) não encontraram diferenças avaliando os cortes (fatias e cubos) de melões armazenados em embalagens rígidas de politereftalato de etileno.

Com relação à escolha das embalagens testadas para os produtos acondicionados em embalagens PET ou isopor envoltos por filme PVC, deve ser realizado um balanço de custos para verificar a viabilidade em cada nicho de comercialização.

Quanto à acidificação, os tratamentos mostraram que o pH diminuiu oferecendo maior segurança de consumo do produto, no período de armazenamento refrigerado, embora deva ser estudado um maior período de imersão dos toletes para possibilitar uma maior difusão do ácido utilizado.

Assim sendo, esse estudo possibilitou verificar que a cadeia produtiva pode ser favorecida com o aproveitamento integral da matéria-prima através da metodologia desenvolvida que consistiu no processamento na forma de conservas, de minimamente processados e de farinhas para incorporação em alimentos, com agregação de valor e obtenção de produtos de qualidade.

\section{Conclusões}

O processamento do palmito pupunha permitiu obter um balanço de massa que demonstrou maior rendimento da parte comestível na cultura irrigada, enquanto a não irrigada apresentou maior porcentagem de bainhas externas e internas, correspondentes a casca. A irrigação também porporcionou maior quantidade de descarte fibroso, o qual foi utilizado para elaboração de farinha e que pode ser incorporada em produtos alimentícios.

Ao processar o palmito pupunha verificou-se que a porção mais nobre (tolete) apresentou menor rendimento que a porção caulinar, sendo que ambos foram processados em conservas e minimamente processados. Para evitar o descarte da parte inferior da pupunha elaboraram-se cubos desuniformes na forma apenas de conservas. No que se trata da irrigação no cultivo de palmito pupunha, foi notório o aumento do rendimento dos produtos provenientes de lavouras com esse manejo.

Esse estudo demonstrou que a cadeia produtiva pode ser favorecida com o aproveitamento integral da matéria-prima através da metodologia desenvolvida que possibilita o processamento do palmito pupunha na forma de conservas, de minimamente processados e de farinhas para 
incorporação em alimentos, com agregação de valor e obtenção de produtos de qualidade. A composição química da farinha desenvolvida revelou teores de umidade e proteínas similares a farinha de trigo, e superiores teores de fibras e cinzas.

As conservas processadas nos diferentes formatos demonstrou ser uma alternativa viável para aproveitamento da matéria-prima. Os valores de $\mathrm{pH}$ de equilíbrio abaixo de 4,5, vácuo de 15 a 18 pollHg e pesquisa de esterilidade negativa estão dentro dos limites exigidos pela legislação vigente, garantindo a segurança e esterilidade comercial dos produtos obtidos.

O tratamento térmico adotando binômios de tempo e temperatura, definidos nesse trabalho, aliados à acidificação possibilitaram a conservação dos produtos sob a forma de conservas em todos os lotes processados.

O palmito minimamente processado acidificado é uma alternativa para a comercialização in natura deste produto e agrega valor a matéria-prima disponibilizando para o consumidor um produto prático e seguro, devido à faixa de $\mathrm{pH}$ atingida, no período de armazenamento refrigerado considerado, independente do tipo de embalagem utilizada.

De posse nos resultados e avaliando as perdas obtidas conclui-se que se faz necessário um levantamento de custo/benefício para que os agricultores através de parcerias junto aos órgãos públicos possam fazer uso desses recursos e não fiquem a mercê de fatores climáticos (como estiagem prolongada) reduzindo os riscos de perdas de safras.

Foi verificada uma grande variação nos rendimentos nos ensaios realizados, demonstrando a necessidade de uma padronização da matéria-prima visando um maior rendimento industrial.

A tecnologia desenvolvida nesse estudo foi difundida ao setor agroindustrial por meio de boletins técnicos e treinamentos teóricos e práticos, aumentando a possibilidade de aproveitamento integral da produção de palmito pupunha, agregando valor à cadeia produtiva.

\section{Agradecimentos}

Os autores agradecem às técnicas do setor de Tecnologia de Alimentos da UEM - campus de Umuarama - Rita Cristina Galli de Oliveira e Meire Franci Polonio Navacchi. Agradecem à SETI Secretaria de Estado Ciência, Tecnologia e Ensino Superior - Programa Universidade sem Fronteiras - Apoio à Agricultura Familiar do estado do Paraná. Agradecem especialmente aos produtores de palmito pupunha da região do Arenito\PR.

\footnotetext{
Abstract

The social and economic importance of the cultivation of heart of palm in the region of Arenito/PR has led to the elaboration of a processing scheme to the complete utilization of raw material, in order to incentive this productive chain. The processing of heart of palm stems proceeding from
} 
crop with and without irrigation was carried out, followed by the analysis of yield by means of mass balance. The results showed that the use of an adequate system of irrigation influences the yield positively. The mass balance allowed us to compare the yield in canned and minimally processed products and the amount of waste and generated residues. The residues were transformed into flour to be used as sources of fiber. The amount destined to the production of canned was divided into 3 categories: rolls (class A), cubes (class B) and irregular cubes (class $C$ ), which were conditioned to acidified brine and submitted to thermal treatment, so that the results would be viable for consumption with $\mathrm{pH}$ under 4.5. With $\mathrm{pH}$ and titratable acidity evaluations, it was possible to verify that the products reached a safe $\mathrm{pH}$, around 4.5, and that the cubes had a more efficient acidification than the rolls. The technology used was sent to those who are interested and live in within the scope of the Extension Project "Program University without Boundaries".

Key-words: heart of palm, yield, acidity of canned, minimally processed products.

\section{Referências}

ANEFALOS, L. C.; TUCCI, M. L. S.; MODOLO, V. A. Uma visão sobre a pupunheira no contexto do mercado de palmitoto. Análises e Indicadores do Agronegócio. v. 2, n.7, 2007.

AOAC - ASSOCIATION OF OFFICIAL ANALYTICAL CHEMISTIS. Official Methods of Analysis of Official Analytical Chemists International. 20 ed. Arlington., 2007.

ARRUDA, M. C.; JACOMINO, A. P.; KLUGE, R. A.; AZZOLINI, M. Temperatura de armazenamento e tipo de corte para melão minimamente processado. Revista Brasileira de Fruticultura, v. 25, n.1, p. 74-76, 2003. http://dx.doi.org/10.1590/S0100-29452003000100022

BARBOSA, J. R.; BELTRAME, S. C.; BRAGATTO, M. M.; DÉBIA, P. J. G.; BOLANHO, B. C.; DANESI, E. D. G. Avaliação da composição e dos parâmetros tecnológicos de farinhas produzidas a partir de subprodutos agroindustriais. In: VII Semana de Engenharia de Alimentos e V Simpósio de Engenharia, Ciência e Tecnologia de Alimentos da UEM. 2011.

BELLEGARD, C. R. G.; RAUPP, D. S.; CHAIMSOHN, F.P.; BORSATO, A.V. Avaliação de procedimentos de acidificação de conservas de palmito foliar de pupunha (Bactris gasipaes Kunth). Acta Scientiarum Agronomy, v. 27, n. 2, p.247-254, 2005.

BERBARI, S. A. G.; PRATI, P.; JUNQUEIRA, V. C. A. Qualidade do palmito da palmeira real em conserva. Ciência e Tecnologia de Alimentos, v.28, p. 135-141, 2008. http://dx.doi.org/10.1590/S0101-20612008000500021

BRASIL. Ministério da Saúde. Anvisa. Resolução no 362, de 29 de junho de 1999. Diário Oficial da União (DOU) 22 de novembro de 1999. Disponível em: 〈http:llwww.anvisa.gov.brllegis|resoll17 99rdc.htm〉. Acesso em: 28 de junho de 2011.

CHAIMSOHN, F. P.; MORSBACH, N.; DURIGAN, M. E.; TREITNY, M. R.; GOMES, E. P. Desenvolvimento de pupunha (Bactris gasipaes Kunth) cultivada para palmito em diferentes regiões do Paraná. Boletim Técnico 67. Londrina: IAPAR, 2002.

CHITARRA, M. I. F.; CHITARRA, A. B. Pós-colheita de frutos e hortaliças. Lavras: Fundação de Apoio ao Ensino Pesquisa e Extensão, 2006. 256 p.

DAMODARAN, S.; PARKIN, K. L.; FENNEMA, O. R. Química de Alimentos de Fennema. trad. Adriano Brandelli. 4 ed. Porto Alegre: Artmed, 2010.

FANTUZZI, E.; PUSCHMANN, R.; VANETTI, M. C. D. Microbiota contaminante em repolho minimamente processado. Ciência e Tecnologia de Alimentos, v. 24, n. 2, p. 207-211, 2004. http://dx.doi.org/10.1590/S010120612004000200008 
DANESI, E. D. G.; EGEA, M. B. Processamento de Conservas Vegetais. Maringá: EDUEM - Fundamentum, n. 64. 2010 .

GALDINO, N. O.; CLEMENTE, E. Palmito de pupunha (Bactris gasipaes Kunth.) composição mineral e cinética de enzimas oxidativas. Ciência e Tecnologia de Alimentos, v. 28, n. 3, p. 540-544, 2008. http://dx.doi.org/10.1590/S0101-20612008000300006

IAL - INSTITUTO ADOLFO LUTZ. Normas analíticas do Instituto Adolfo Lutz: Métodos físicos e químicos para análise de alimentos. 4 ed. São Paulo: IAL, 2005.

INSTITUTO AGRONÔMICO DO PARANÁ - IAPAR. Curso sobre cultivo, processamento e comercialização de palmito de pupunha. Circular Técnica, Londrina, v. 117, p. 1-150, 2001.

JUNQUEIRA, M. S.; SOARES, N. F. F.; REIS, R. C.; CARNEIRO, J. D. S.; BENICIO, R. T.; YOKOTA, S. R. C. Efeito de embalagens ativas no escurecimento enzimático de batatas (Solanum tuberosum) fatiada e minimamente processada. Semina: Ciências Agrárias, v. 30, n. 3, p. 613-618, 2009.

KAPP, E. A.; PINHEIRO, J. L.; RAUPP, D. S.; CHAIMSOHN, F. P. Tempo de preservação de tolete de palmito pupunha (Bactris gasipaes) minimamente processados e armazenados sob refrigeração. Publicatio UEPG: Ciências Exatas e da Terra, Ciências Agrárias e Engenharias, v. 9, n.3, p. 51-57, 2003.

KUlTChetSCHI, L.; CHAIMSOHN, F. P.; GARDINGO, J. R. Palmito pupunha (Bactris gasipaes Kunth): a espécie, cultura, manejo agronômico, usos e processamentos. Ponta Grossa: Editora UEPG, 2001.

MONTEIRO, M. A. M.; STRINGHETA, P. C.; COELHO, D. T.; MONTEIRO, J. B. R. Estudo químico de alimentos formulados à base de palmito Bactris gasipaes H. B. K. (pupunha) desidratado. Ciência e Tecnologia de Alimentos, v. 22, n. 3, 2002. http://dx.doi.org/10.1590/S0101-20612002000300002

MORSBACH, N.; RODRIGUES, A. S.; CHAIMSOHN, F.P.; TREITNY, M. R. Pupunha para palmito: cultivo no Paraná. Circular Técnica IAPAR, v. 103, p. 56, 1998.

PASCHOALINO, J. E. Processamento de Hortaliças. Manual técnico. ITAL: Campinas, 1994.

PASCHOALINO, J. E.; BERNHARDT, L. W., BOVI, M.L.A, BERBARI, S.A.G., FEREIRA, V.L.P. A industrialização do palmito pupunha. Manual técnico. ITAL: Campinas, 1997.

PEREIRA, J.; SILVA, R.P.G.; NERY, F.C.; VILELA, E.R. Comparação entre a composição química determinada e a declarada na embalagem de diferentes marcas de pão de queijo. Ciência Agrotécnica. v. 29, n. 3, p. 623-628, 2005. http://dx.doi.org/10.1590/S1413-70542005000300017

PINELI, L. L. O.; MORETTI, C. L.; ALMEIDA, G. C.; ONUKI, A. C. A.; NASCIMENTO, A. B. G. Caracterização química e física de batatas 'Ágata' minimamente processadas, embaladas sob diferentes atmosferas modificadas ativas. Pesquisa Agropecuária Brasileira, v. 40, n. 10, p. 1035-1041, 2005. http://dx.doi.org/10.1590/S0100204X2005001000013

PROTZEK, E.C.; FREITAS, R.J.S.; WASCZYNSKJ, N. Aproveitamento do bagaço de maçã na elaboração de biscoitos ricos em fibras alimentares. Boletim do Centro de Pesquisa e Processamento de Alimentos, v. 16, n. 2, p. 263-275, 1998.

SARZI, B.; DURIGAN, J. F. Avaliação física e química de produtos minimamente processados de abacaxi "pérola". Revista Brasileira de Fruticultura, v. 24, n. 2, p. 333-337, 2002. http://dx.doi.org/10.1590/S010029452002000200012

TACO-Tabela Brasileira de Composição de Alimentos. Disponível em: http://www.unicamp.br/nepa/taco/CampinasSP. Acesso em: 11 abril 2011.

TEIXEIRA, G. H. A.; DURIGAN, J. F.; MATTIUZ, B.; ROSSI JÚNIOR, O. D. Processamento mínimo de mamão "Formosa". Ciência e Tecnologia de Alimentos, v. 21, n. 1, p. 47-50, 2001. http://dx.doi.org/10.1590/S010120612001000100011

Submetido em 01 ago. 2011, Aceito para publicação em 08 ago. 2012. 